\title{
General practitioners, revalidation and appraisal: a cross sectional survey of attitudes, beliefs and concerns in Lincolnshire
}

\author{
fo Middlemass $^{1}$ E A Niroshan Siriwardena ${ }^{1,2}$
}

Background All general practitioners (GPs) are expected to have an appraisal from 2002 and the first cohort will experience revalidation in 2005. Although there is a link between appraisal and revalidation, this has yet to be clarified.

Objective To investigate the knowledge, attitudes and beliefs of GPs towards revalidation and appraisal.

Design Cross sectional survey.

Setting Lincolnshire, UK.

Participants General practitioners.

Method In 2000 a self-administered postal questionnaire survey was sent to all 343 GP principals on the list of Lincolnshire Health Authority. The questionnaire consisted of 47 attitudinal statements on appraisal and revalidation. It also included open questions on concerns about appraisal and revalidation and questions on attributes of responders.

Results Of the 343 GPs sent questionnaires, 272 (79\%) replied. Lincolnshire GPs had more positive attitudes towards appraisal than towards revalidation. They welcomed appraisal provided that it had local ownership and took into account their views and concerns on the process. Other factors that correlated with a positive attitude towards appraisal included agreement that the purpose of appraisal is educational and that it should result in an agreed development plan. Those who had a positive view of appraisal were more likely to agree set objectives. Previous experience of appraisal either as an appraiser or appraisee was associated with a positive attitude towards appraisal. General practitioners who felt they had more control over the process tended to be more positive. General practitioners who were in favour of appraisal were also more likely to be in favour of revalidation and agree that appraisal formed part of the revalidation process. They were less likely to feel that there was a hidden agenda on the part of government and more likely to agree that revalidation would provide evidence of acceptable care being provided to patients. Time involved and lack of resources were the two main concerns.

Conclusions A better understanding of knowledge, beliefs and attitudes towards appraisal will ultimately help in setting up a successful appraisal system for GPs. The current emphasis on appraisal as an educational tool will help to foster positive attitudes. The relationship between appraisal and revalidation needs to be clarified. Concerns relating to lack of time and resources for appraisal and revalidation need to be addressed by primary care organisations.

Keywords education, medical, continuing/*standards; *clinical competence; family practice/* ${ }^{\star}$ standards/ methods; attitude; educational measurement; questionnaires; England.

Medical Education 2003;37:778-785

\section{Introduction}

Revalidation is currently being introduced by the UK General Medical Council (GMC) as a means of ensuring a doctor's fitness to practise. ${ }^{1}$ Annual appraisal,

\footnotetext{
${ }^{1}$ West Lincolnshire Primary Care Trust, Lincoln, UK

${ }^{2}$ De Montfort University, Leicester, UK

Correspondence: Jo Middlemass, Clinical Governance Manager, West Lincolnshire Primary Care Trust, Cross O'Cliff Court, Bracebridge, Lincoln LN4 2HN, UK. Tel: 00441522 513355; E-mail: Jo.Middlemass@westlincs-pct.nhs.uk
}

first suggested by the Chief Medical Officer, ${ }^{2}$ is being introduced alongside revalidation and forms part of the National Health Service (NHS) plan. ${ }^{3}$ Appraisal is to be an annual, educational, formative process that helps doctors prepare for revalidation and equips them for lifelong learning, whereas revalidation is to be carried out every 5 years and is a summative process that doctors will either pass or fail.

The various models suggested for appraisal and revalidation may have served to increase confusion and raise anxiety within the medical profession. ${ }^{4}$ Since 


\section{Key learning points}

All GPs are expected to have an appraisal from 2002 and the first cohort will experience revalidation in 2005.

Appraisal for GPs is to be locally implemented and funded by primary care organisations according to national standards.

A better understanding of knowledge, beliefs and attitudes towards appraisal will help in setting up a successful appraisal system for GPs.

This study highlights the belief that appraisal, as an educational tool, will help to foster positive attitudes towards these processes and will be welcomed if it is locally owned and takes into account GPs' views and concerns. Concerns, particularly relating to lack of time and resources for appraisal and revalidation, need to be addressed by primary care organisations.
Southgate and Pringle ${ }^{5}$ outlined the template for revalidation in general practice there has been vigorous debate on the purpose of revalidation as well as the relative merits and drawbacks of alternative approaches. ${ }^{6-8}$ The Sheffield model from ScHARR ${ }^{9}$ has helped to clarify the purpose and process of appraisal but lack of funding, emphasis on local implementation and doubts about the future role of the GMC have left many doctors' leaders and primary care organisations uncertain about how to proceed. Little is known about the views of general practitioners (GPs) towards revalidation and appraisal although it is clear that these attitudes will influence local implementation and be critical to the nature and success of this process.

This study set out to investigate the knowledge, attitudes and beliefs of GPs in Lincolnshire towards appraisal and revalidation and to explore possible factors that may be barriers or facilitators of this process in primary care.

\section{Method}

All 343 GP principals on the medical list in Lincolnshire were invited to complete a postal questionnaire between June and September 2000. Questionnaires were sent out with a covering letter from clinical governance leaders of primary care organisations in the county. The questionnaire asked about personal attributes of the respondents such as age, sex, hours worked, years in practice and previous experience of appraisal or appraisal training. There were also open questions on the personal and professional attributes that GPs would look for in an appraiser and their concerns about an appraisal system. The main body of the questionnaire consisted of items worded as attitudinal statements on issues relating to revalidation and appraisal. The statements were identified from the literature and informal interviews with GPs. These were tested and refined on the basis of a small number of pilot questionnaires. The final version consisted of 47 attitudinal statements. A Likert-type format with five response codes ranging from $1=$ strongly agree to $5=$ strongly disagree was used. For analysis purposes, the strongly agree/agree and strongly disagree/disagree categories were combined, keeping the middle category of neutral. A reminder questionnaire was sent to non-responders 6 weeks after the initial questionnaire. The completed questionnaires were analysed using spsspc. ${ }^{10}$ Responses were compared using Spearman's correlation. The internal consistency of attitude statements (after reversing the coding for positive statements) was calculated using Cronbach's alpha.

\section{Results}

Of the 343 Lincolnshire GPs sent questionnaires, 272 $(79 \%)$ returned completed questionnaires after two mailings. Responders were similar to non-responders in terms of age and sex (Table 1). Cronbach's alpha was 0.78 for the 47 statements, indicating a high degree of internal consistency between the responses to attitude statements. General practitioners were more in favour of appraisal than revalidation but were not strongly in favour of either process (Table 2).

Table 1 Comparison of responders and non-responders in respect of age and sex

\begin{tabular}{|c|c|c|c|c|}
\hline \multirow[b]{2}{*}{ Characteristic } & \multicolumn{2}{|c|}{$\begin{array}{l}\text { Respondents } \\
(n=272)\end{array}$} & \multicolumn{2}{|c|}{$\begin{array}{l}\text { All Lincolnshire } \\
\text { GPs }(n=343)\end{array}$} \\
\hline & Number & $\%$ & Number & $\%$ \\
\hline \multicolumn{5}{|l|}{ Age range (years) } \\
\hline $25-34$ & 33 & $12 \cdot 1$ & 43 & $12 \cdot 5$ \\
\hline $35-44$ & 119 & $43 \cdot 7$ & 161 & $46 \cdot 9$ \\
\hline $45-54$ & 89 & $32 \cdot 7$ & 109 & $31 \cdot 7$ \\
\hline $55+$ & 25 & $9 \cdot 2$ & 30 & $8 \cdot 7$ \\
\hline Data missing & 6 & $2 \cdot 2$ & & \\
\hline \multicolumn{5}{|l|}{ Sex } \\
\hline Male & 198 & $72 \cdot 8$ & 268 & $78 \cdot 1$ \\
\hline Female & 68 & $25 \cdot 0$ & 75 & $21 \cdot 9$ \\
\hline Data missing & 6 & $2 \cdot 2$ & & \\
\hline
\end{tabular}

For age: $\chi^{2}=0.36$, d.f. $=3, P=0.95$.

For sex: $\chi^{2}=1 \cdot 1$, d.f. $=2, P=0 \cdot 29$. 
Table 2 Responses to attitude statements on appraisal and revalidation

Number (\%) of 272 GPs responding

\begin{tabular}{|c|c|c|c|c|c|c|c|c|}
\hline & \\
\hline \multirow[b]{2}{*}{ Statement } & \multicolumn{2}{|c|}{$\begin{array}{l}\text { Agree or } \\
\text { strongly agree }\end{array}$} & \multicolumn{2}{|c|}{ Neutral } & \multicolumn{2}{|c|}{$\begin{array}{l}\text { Disagree or } \\
\text { strongly } \\
\text { disagree }\end{array}$} & \multicolumn{2}{|c|}{ Missing data } \\
\hline & No. & $(\%)$ & No. & $(\%)$ & No. & $(\%)$ & No. & $(\%)$ \\
\hline \multicolumn{9}{|l|}{ Overall } \\
\hline Broadly in favour of appraisal & 162 & $(59 \cdot 6)$ & 62 & $(22 \cdot 8)$ & 47 & $(17 \cdot 3)$ & 1 & $(0 \cdot 4)$ \\
\hline Broadly in favour of revalidation & 136 & $(50 \cdot 0)$ & 67 & $(24 \cdot 6)$ & 68 & $(25 \cdot 0)$ & 1 & $(0 \cdot 4)$ \\
\hline \multicolumn{9}{|l|}{ Understanding of differences between appraisal and revalidation } \\
\hline $\begin{array}{l}\text { Difference between appraisal and revalidation poorly } \\
\text { understood }\end{array}$ & 208 & $(76 \cdot 5)$ & 48 & $(17 \cdot 6)$ & 13 & $(4 \cdot 8)$ & 3 & $(1 \cdot 1)$ \\
\hline Two systems of appraisal and revalidation are interlinked & 176 & $(64 \cdot 7)$ & 67 & $(24 \cdot 6)$ & 27 & $(9 \cdot 9)$ & 2 & $(0 \cdot 7)$ \\
\hline \multicolumn{9}{|l|}{ Purpose of appraisal and revalidation } \\
\hline Main purpose of appraisal is educational & 146 & $(53 \cdot 7)$ & 41 & $(15 \cdot 1)$ & 82 & $(30 \cdot 1)$ & 3 & $(1 \cdot 1)$ \\
\hline Main purpose of revalidation is performance monitoring & 220 & $(80 \cdot 9)$ & 31 & $(11 \cdot 4)$ & 20 & $(7 \cdot 4)$ & 1 & $(0 \cdot 4)$ \\
\hline \multicolumn{9}{|l|}{ What evidence should be provided? } \\
\hline $\begin{array}{l}\text { Revalidation will require having a portfolio of evidence of } \\
\text { good practice }\end{array}$ & 148 & $(54 \cdot 4)$ & 93 & $(34 \cdot 2)$ & 31 & $(11 \cdot 4)$ & 0 & $(0)$ \\
\hline $\begin{array}{l}\text { GPs would not mind providing evidence of their practice for } \\
\text { revalidation assessment }\end{array}$ & 183 & $(67 \cdot 3)$ & 58 & $(21 \cdot 3)$ & 29 & $(10 \cdot 7)$ & 2 & $(0 \cdot 7)$ \\
\hline $\begin{array}{l}\text { GPs would be comfortable having their care evaluated in terms } \\
\text { of statements as detailed in Good Medical Practice }\end{array}$ & 159 & $(58 \cdot 5)$ & 66 & $(24 \cdot 3)$ & 45 & $(16 \cdot 5)$ & 2 & $(0 \cdot 7)$ \\
\hline $\begin{array}{l}\text { GPs would be comfortable in having agreed objectives set and } \\
\text { being accountable for these at their next appraisal }\end{array}$ & 180 & $(66 \cdot 7)$ & 58 & $(21 \cdot 3)$ & 32 & $(11 \cdot 8)$ & 2 & $(0 \cdot 7)$ \\
\hline \multicolumn{9}{|l|}{ Links to educational plans } \\
\hline The GP appraisal should result in an agreed development plan & 212 & $(77 \cdot 9)$ & 53 & $(19 \cdot 5)$ & 7 & $(2 \cdot 6)$ & 0 & $(0)$ \\
\hline $\begin{array}{l}\text { Revalidation will include providing evidence of appraisal and } \\
\text { a learning plan }\end{array}$ & 181 & $(66 \cdot 5)$ & 75 & $(27 \cdot 6)$ & 15 & $(5 \cdot 5)$ & 1 & $(0 \cdot 4)$ \\
\hline \multicolumn{9}{|l|}{ Process } \\
\hline $\begin{array}{l}\text { Would trust the Royal Colleges to come up with a revalidation } \\
\text { tool appropriate for GPs }\end{array}$ & 67 & $(24 \cdot 6)$ & 75 & $(27 \cdot 6)$ & 128 & $(47 \cdot 4)$ & 2 & $(0 \cdot 7)$ \\
\hline The appraisal process should be developed locally & 200 & $(73 \cdot 5)$ & 44 & $(16 \cdot 2)$ & 28 & $(10 \cdot 3)$ & 0 & $(0)$ \\
\hline $\begin{array}{l}\text { Would like to be involved in setting up revalidation } \\
\text { process locally }\end{array}$ & 92 & $(33 \cdot 8)$ & 93 & $(34 \cdot 2)$ & 85 & $(31 \cdot 3)$ & 2 & $(0 \cdot 7)$ \\
\hline $\begin{array}{l}\text { GPs being appraised will be able to negotiate the terms and } \\
\text { contents of their appraisals with their appraisers }\end{array}$ & 105 & $(38 \cdot 6)$ & 107 & $(39 \cdot 3)$ & 59 & $(21 \cdot 7)$ & 1 & $(0 \cdot 4)$ \\
\hline $\begin{array}{l}\text { Expect to be able to negotiate educational aims and } \\
\text { objectives with appraiser }\end{array}$ & 216 & $(79 \cdot 4)$ & 42 & $(15 \cdot 4)$ & 8 & $(2 \cdot 9)$ & 6 & $(2 \cdot 2)$ \\
\hline $\begin{array}{l}\text { GP appraisal based on self-assessment by appraisee } \\
\text { with appraiser facilitation }\end{array}$ & 109 & $(40 \cdot 1)$ & 126 & $(46 \cdot 3)$ & 33 & $(12 \cdot 1)$ & 4 & $(1 \cdot 5)$ \\
\hline \multicolumn{9}{|l|}{ Where should the appraisal take place? } \\
\hline Would want the appraisal to be held at the practice & 201 & $(73 \cdot 9)$ & 66 & $(24 \cdot 3)$ & 4 & $(1 \cdot 5)$ & 1 & $(0 \cdot 4)$ \\
\hline Appraisals should take place in the normal working day & 224 & $(82 \cdot 4)$ & 23 & $(8 \cdot 5)$ & 21 & $(7 \cdot 7)$ & 4 & $(1 \cdot 5)$ \\
\hline No patient time should be lost undertaking an appraisal & 162 & $(59 \cdot 6)$ & 30 & $(11 \cdot 0)$ & 79 & $(29 \cdot 0)$ & 1 & $(0 \cdot 4)$ \\
\hline \multicolumn{9}{|l|}{ Characteristics of appraiser/appraisal } \\
\hline Appraisal should be a peer review system & 189 & $(69 \cdot 5)$ & 64 & $(23 \cdot 5)$ & 19 & $(7 \cdot 0)$ & 0 & $(0)$ \\
\hline $\begin{array}{l}\text { The appraiser should be a GP currently working in } \\
\text { general practice }\end{array}$ & 248 & $(91 \cdot 2)$ & 16 & $(5 \cdot 9)$ & 8 & $(2 \cdot 9)$ & 0 & $(0)$ \\
\hline Would want to choose own appraiser & 139 & $(51 \cdot 1)$ & 108 & $(39 \cdot 7)$ & 22 & $(8 \cdot 1)$ & 3 & $(1 \cdot 1)$ \\
\hline \multicolumn{9}{|l|}{ Confidentiality } \\
\hline Revalidation is not a confidential process & 119 & $(43 \cdot 8)$ & 60 & $(22 \cdot 1)$ & 91 & $(33 \cdot 5)$ & 2 & $(0 \cdot 7)$ \\
\hline $\begin{array}{l}\text { Following appraisal only the identified training needs } \\
\text { should be disclosed to others }\end{array}$ & 137 & $(50 \cdot 8)$ & 82 & $(30 \cdot 1)$ & 48 & $(17 \cdot 6)$ & 5 & $(1 \cdot 8)$ \\
\hline
\end{tabular}


Table 2 Continued

Number (\%) of 272 GPs responding

\begin{tabular}{|c|c|c|c|c|c|c|c|c|}
\hline \multirow[b]{2}{*}{ Statement } & \multicolumn{2}{|c|}{$\begin{array}{l}\text { Agree or } \\
\text { strongly agree }\end{array}$} & \multicolumn{2}{|c|}{ Neutral } & \multicolumn{2}{|c|}{$\begin{array}{l}\text { Disagree or } \\
\text { strongly } \\
\text { disagree }\end{array}$} & \multicolumn{2}{|c|}{$\begin{array}{l}\text { Missing } \\
\text { data }\end{array}$} \\
\hline & No. & $(\%)$ & No. & $(\%)$ & No. & $(\%)$ & No. & $(\%)$ \\
\hline \multicolumn{9}{|l|}{ Training and resources for appraisal } \\
\hline $\begin{array}{l}\text { There should be training for all GPs undertaking appraisal } \\
\text { whether as an appraisee or appraiser }\end{array}$ & 234 & $(86 \cdot 0)$ & 31 & $(11 \cdot 4)$ & 7 & $(2 \cdot 6)$ & 0 & $(0)$ \\
\hline Currently there is a lack of trained GPs able to appraisers & 223 & $(82 \cdot 0)$ & 46 & $(16 \cdot 9)$ & 3 & $(1 \cdot 1)$ & 0 & $(0)$ \\
\hline There are sufficient resources to support appraisal training & 16 & $(5 \cdot 9)$ & 20 & $(7 \cdot 4)$ & 236 & $(86 \cdot 8)$ & 0 & $(0)$ \\
\hline GP trainers should be exempt from appraisals & 18 & $(6 \cdot 6)$ & 11 & $(4 \cdot 0)$ & 243 & $(89 \cdot 3)$ & 0 & $(0)$ \\
\hline
\end{tabular}

\section{Purpose of appraisal and revalidation}

Over three-quarters $(77 \cdot 3 \%)$ of respondents thought that the difference between appraisal and revalidation was poorly understood. Most felt that revalidation was part of performance monitoring $(81 \cdot 2 \%)$. Nearly twothirds $(59 \%)$ felt that the government had a hidden agenda, revealing suspicions about the motives for introducing these processes. Over half the respondents $(54.3 \%)$ believed that the purpose of appraisal was educational. Most (94.5\%) believed that a variety of factors could lead to poor performance within a practice, of which a poorly performing doctor was only one.

\section{What evidence should be provided?}

Over half the respondents (58.9\%) agreed that their practice should be evaluated in terms of statements detailed in Good Medical Practice, ${ }^{11}$ which outlines the duties and responsibilities of a family doctor. Most Lincolnshire GPs were aware of this document (unpublished data). Over two-thirds stated that they would agree to provide evidence of their practice $(67.8 \%)$ and over half $(54 \cdot 4 \%)$ understood that revalidation would require a portfolio of evidence. General practitioners thought that audit, evidence of training and practice objectives were relevant data to be gathered for appraisal. Over two-thirds of GPs $(70 \cdot 1 \%)$ agreed with statements linking appraisal with continuing professional development and over three-quarters (77.9\%) agreed that the GP appraisal should result in an agreed development plan. Less than half $(44 \cdot 1 \%)$ of GPs in Lincolnshire thought that revalidation was a confidential process and approximately half $(51.3 \%)$ thought that only the training needs identified from the appraisal should be disclosed to others.

\section{Developing revalidation and appraisal}

Only a quarter of respondents $(24.8 \%)$ were in favour of relying on the Royal College of General Practitioners (RCGP) to come up with a revalidation tool. It is not clear whether GPs questioned the motives of the RCGP, its competence or the appropriateness of it devising such a tool. This leaves some doubt about the College's accredited professional development (APD) as a route to revalidation. Most wanted the appraisal process to be developed locally. Over threequarters $(81.2 \%)$ of GPs thought that they would be able to negotiate educational aims and objectives with their appraiser, but only a third $(38.7 \%)$ believed that they would be able to negotiate the format of the appraisal. The majority of GPs (74.2\%) wanted their appraisal to be held in the practice; many $(83.6 \%)$ felt strongly that it should take place during the working day and over half $(59.8 \%)$ did not want any patient time to be lost by undertaking an appraisal. However, it was not clear whether this meant that they were willing to alter surgery times or whether they wanted locum cover.

\section{Who should be the appraiser?}

Almost all respondents $(91 \cdot 2 \%)$ wanted their appraiser to be a practising GP and most $(69 \cdot 5 \%)$ felt that appraisal should be a peer review process. Half $(51 \cdot 7 \%)$ wanted to be able to choose their appraiser. They sought an appraiser who was non-threatening, experienced, empathetic and sympathetic, and one who commanded 
the confidence and respect of fellow professionals. They also wanted appraisers to have experience as trainers or teachers. Although some wanted appraisers to have additional qualifications, they were less in favour of academics as appraisers. Only a quarter of respondents had someone in mind as their appraiser.

\section{Training}

The vast majority of GPs (86.5\%) wanted all GPs to be trained to engage in the appraisal process. Most (82\%) also agreed that there was a lack of trained appraisers, a belief which was borne out by low rates of self-reporting of training for both appraisers and appraisees. While $11.8 \%$ of GPs had undergone appraiser training, fewer $(7 \cdot 1 \%)$ had had appraisee training. Most GPs $(86 \cdot 8 \%)$ were unconvinced that there would be sufficient resources to support appraisal training.

\section{Concerns}

Responses to the open question revealed that time involved in the appraisal process and lack of resources were major concerns (Table 3). General practitioners were suspicious that there was an element of manipulation by government in the process. They were worried that the process would be stressful and threatening and were concerned about who their appraisers would be. There were also concerns that the system itself was too rigid and would serve to demoralise good GPs rather than to weed out poorly performing GPs.

\section{Factors correlating with a positive attitude to appraisal}

Those in favour of appraisal tended to have had previous experience of appraisal as an educational tool (Table 4). These GPs were also more likely to perceive a degree of control over the process, in that they could, for example, negotiate aims and objectives. They expected a development plan to be a product of their appraisal and were comfortable with setting objectives and being accountable for these at their next appraisal. Those who were in favour of appraisals believed there should be appraisal training for all GPs. Those in favour of appraisals disagreed that there was a lack of commitment on the part of GPs to the process of appraisals. There was also a correlation between positive attitudes to appraisal amongst those who had received appraiser training, for example those who were GP trainers.

General practitioners in favour of appraisal also had positive views on revalidation. They were less likely to suspect a hidden agenda on the part of government.
They felt that revalidation would provide evidence that acceptable care was being provided to patients. They were also more likely to agree that having an appraisal formed part of the revalidation process. There was a weak correlation with age, with older GPs slightly more in favour of appraisal.

\section{Discussion}

The results of this survey provide some insight into the views of GPs towards appraisal and revalidation just before their introduction. Although there is now greater knowledge about when and how these processes will be undertaken, the emphasis on local implementation for appraisal and lack of information about revalidation means that considerable uncertainty remains.

The high response rate may have been due to the fact that appraisal and revalidation are areas of concern to GPs. The high overall response rate, good response to individual survey items and spread of responses to attitudinal statements supported the face and content validity of the questionnaire. The high internal consistency suggested that the instrument was reliable. The findings are particularly of interest to Lincolnshire GPs. However, there is no reason to suspect that the attitudes of Lincolnshire GPs should differ from those of GPs in other areas of the country. General practitioner non-principals were not considered in this survey, and further research to take in the views of this growing minority of professionals may be warranted.

An area of tension, which was borne out by this study, involved the conflict between the formative nature of the educational appraisal that aims to support and motivate doctors with the performance monitoring function of revalidation. There was real concern that appraisal might not detect incompetent doctors, but that it could demoralise good ones. There was also awareness that a number of factors, such as health problems, domestic circumstances and family breakdown $^{12}$ might lead to a poor performance within practice. General practitioners wanted their appraiser to be a practising GP and appraisal to be a peer review process. This supports arguments for peer appraisal as peers are likely to have a more comprehensive view of the appraisee's job performance, ${ }^{13}$ although there is also a view that peer appraisal might be seen as 'grassing' on colleagues. Personal characteristics of an appraiser were seen as important in this survey. Riley ${ }^{14}$ suggested that a successful appraiser should have excellent interpersonal skills, relate to and empathise with the appraisee, but be able to give feedback in a diplomatic, non-judgemental way, giving support and counselling when necessary. ScHARR ${ }^{9}$ envisaged that 
Table 3 Main concerns about appraisal system for GPs: number of responses

\begin{tabular}{ll}
\hline Main concerns about appraisal system for GPs & $\begin{array}{l}\text { Number of } \\
\text { responses }\end{array}$ \\
\hline Time involved & 73 \\
2 Lack of resources & 44 \\
3 Government agenda, control/manipulation, & 39 \\
$\quad$ jumping through hoops, OFSTED for doctors & \\
4 Process stressful/threatening & 23 \\
5 Anxiety about who the appraiser would be & 21 \\
6 That the criteria wouldn't measure what it & 19 \\
$\quad$ was supposed to - too rigid/prescriptive, & \\
$\quad$ no flexibility & 17 \\
7 Lack of appraisal training & 15 \\
8 Lack of confidentiality & 7 \\
9 Loss of individuality, independence & 5 \\
10 That it won't weed out poorly performing & \\
$\quad$ doctors, but demoralise good ones & \\
\hline
\end{tabular}

there should be a core group of appraisers from which GPs could choose.

Confidentiality was also of concern to practitioners. SCOPME ${ }^{15}$ stated that confidentiality should be respected in appraisals. Oxley ${ }^{16}$ envisaged that the only exception to this would be if the appraisee's clinical work was endangering patients but acknowledged that it was unlikely that appraisal would be the only source of this information. ScHARR ${ }^{9}$ considered that serious underperformance should be dealt with separately from appraisal but there has been little consideration of what should happen when a practitioner is found to be seriously underperforming. This survey looks at attitudes from the perspective of practitioners undergoing appraisal but other stakeholders are also likely to have important roles. The role of clinical governance leaders, the functions of the deanery or issues around provision and resourcing of remedial training have not been clarified. Concerns over indemnity for appraisers, when, for example, an appraisal is satisfactory but the practitioner is later found to be seriously underperforming, have yet to be addressed.

The evidence required for appraisal continues to be a matter for debate. Although audits were seen as key elements for appraisal in this study, these often reflect the care provided by the practice team as a whole rather than that provided by an individual member. Practice aims and objectives would not indicate individual

Table 4 Characteristics of GPs in favour of appraisal

GPs who are in favour of appraisal are also more likely to:

Think that the purpose of appraisal is educational

Agree that appraisal should result in an agreed development plan

Agree that appraisal covers areas such as educational, personal and

professional development

Also be in favour of revalidation

Be comfortable in having agreed objectives set and being

accountable for these at the next appraisal

Agree there should be appraisal training for all GPs

Have had training as an appraiser

Have had previous involvement as an appraiser

Have had previous involvement as an appraisee

Think that they are able to negotiate the terms and contents of their educational appraisal with their appraiser

Think that they are able to negotiate the aims and objectives of their educational appraisal with their appraiser

Believe that appraisal is based on self-assessment by the appraisee with appraiser facilitation

Agree that that the clinical governance lead would be a good choice as appraiser

Disagree that no patient time should be lost undertaking an appraisal

Think that having an appraisal forms part of the revalidation process

Agree that revalidation monitors GPs performance against agreed standards and targets

Agree that revalidation would provide evidence of acceptable care being provided to patients in order to continue practising

$\mathrm{Be}$ in the older age range
Spearman's rank correlation coefficient (two-tailed)

$$
\begin{aligned}
& r_{\mathrm{s}}=0.287 P<0.01 \quad(P=000) \\
& r_{\mathrm{s}}=0.228 P<0.01 \quad(P=000) \\
& r_{\mathrm{s}}=0.186 P<0.01 \quad(P=0.002) \\
& r_{\mathrm{s}}=0.684 P<0.01 \quad(P=0.000) \\
& r_{\mathrm{s}}=0.218 P<0.01 \quad(P=0.000) \\
& r_{\mathrm{s}}=0.129 P<0.05(P=0.034) \\
& r_{\mathrm{s}}=0.122 P<0.05(P=0.047) \\
& r_{\mathrm{s}}=0.251 P<0.01 \quad(P=0.000) \\
& r_{\mathrm{s}}=0.187 P<0.01(P=0.002) \\
& r_{\mathrm{s}}=0.142 P<0.05(P=0.020) \\
& r_{\mathrm{s}}=0.135 P<0.05(P=0.028) \\
& r_{\mathrm{s}}=0.134 P<0.05(P=0.029) \\
& r_{\mathrm{s}}=0.167 P<0.01(P=0.006) \\
& r_{\mathrm{s}}=-0.139 P<0.05(P=0.022) \\
& r_{\mathrm{s}}=0.310 P<0.01 \quad(P=0.000) \\
& r_{\mathrm{s}}=0.159 P<0.01(P=0.009) \\
& r_{\mathrm{s}}=0.263 P<0.01(P=0.000) \\
& r_{\mathrm{s}}=0.132 P<0.5(P=0.032)
\end{aligned}
$$


performance either. A portfolio of training would yield a record of individual training undertaken but may not show what the individual had gained from the training experience unless this was recorded. Weightman ${ }^{12}$ details record cards, complaints, mistakes, comparison with other people's work, information from colleagues as well as personal files, sickness and absence records as information that could be obtained for appraisal. Peer rating using 360 -degree surveys ${ }^{17}$ are starting to be used in some areas. The personal learning plan, a form of learning contract or agreement, will be one outcome of appraisal and will be reviewed regularly as part of subsequent appraisals.

The advantage of effective educational appraisal is that it can provide support, mentorship, recognition and the challenges required to motivate GPs, ${ }^{18}$ as well as enable them to reflect on performance in order to address personal and service needs for learning. ${ }^{19}$ It is envisaged that a personal learning plan will be negotiated, agreed and signed by both appraiser and appraisee and that the whole plan or the learning needs arising from it could be shared within the organisation, ${ }^{14}$ although the link with continuing professional development has yet to be operationalised.

Training will be a key issue both for appraisers and appraisees. Training in appraisal skills is important, not only at inception, but also as the appraisal scheme continues in order to check on and refresh people's skills. Without appropriate training and careful development, a scheme could easily degenerate into a paper exercise. Training also has resource implications. ${ }^{20}$ Potential problems will occur if a practitioner has a satisfactory appraisal but is subsequently found to be poorly performing.

Appropriate resourcing was a major concern for participants in this study and will be key to the success of the appraisal system. Although initial appraiser training will be funded centrally, this accounts for a very small proportion of the overall costs. There will also be costs for the remaining appraiser training and for appraisee training for all GPs. Adequate resources are needed for preparation, undertaking the appraisal and recording the process. The time involved has been estimated at between 4.5 and 6.5 hours. Primary care organisations will need to have policies on the provision and funding of locum cover. ${ }^{17}$ There will be additional costs for managing and co-ordinating the appraisal system. Outcomes from appraisals, such as identified educational needs, may also have resource implications. Although funding for appraisal has been allocated to primary care trusts (PCTs) as part of their unified budgets, this is unlikely to fully meet the full costs of the appraisal system. Given the other demands on budgets and opportunity costs, this is likely to lead to potential tensions between GPs and primary care organisations.

\section{Conclusion}

A better understanding of knowledge, beliefs and attitudes towards appraisal will ultimately help in setting up a successful appraisal system for GPs. The main challenge for the introduction of appraisal is to build on positive attitudes and allay fears. Clarifying the terminology to make appraisal explicitly educational will be helpful in allaying fears and the Department of Health has already gone some way along this path. There also needs to be 'clear, blue water' between appraisal and revalidation in practitioners' minds to avoid confusion between the purpose, methods and outcomes of these processes. Any system should also consider the process of the appraisals and look at issues such as confidentiality to ensure that GPs' concerns are addressed as far as possible. This could be done by working with opinion leaders, emphasising that appraisal will have a positive educational outcome and ensuring that practitioners have a degree of ownership in the process. Urgent consideration of the financial and resource implications to undertake appraisals is needed.

\section{Contributors}

JM and ANS had the initial idea for the study. JM developed the instrument and undertook the survey. Both authors undertook statistical and data analysis and contributed to the drafting, revision and approval of the final version of the paper. JM is guarantor for the paper.

\section{Acknowledgements}

We thank Lincolnshire GPs and the support of the West Lincolnshire Primary Care Trust. We are grateful to Professor Aly Rashid, Professor Mike Pringle and Dr Amar Rughani for their comments on the paper. Professor Anthony Avery is JM's MPhil supervisor.

\section{Funding}

West Lincolnshire Primary Care Trust fund JM and ANS. JM was also supported by a Health Services Training Grant from the NHS Executive to undertake her MPhil. Trent Focus assisted funding for ANS. There are no competing interests. 


\section{References}

1 General Medical Council. Revalidating Doctors. London: General Medical Council 2000.

2 Department of Health. Supporting Doctors, Protecting Patients London: Department of Health 1999.

3 Department of Health. The NHS Plan. London: Department of Health 2000.

4 Hayes S. GMC's proposals for revalidation. Appraisal is helpful only if done well. BMF 2001;322:358.

5 Southgate L, Pringle M. Revalidation in the United Kingdom: general principles based on experience in general practice. BMF 1999;319:1180-3.

6 Wakeford R. GMC's proposals for revalidation would not be accurate, economical or fair. BMf 2000;321:1220.

7 Newble D. GMC's proposals for revalidation. Purpose of revalidation process must be agreed on. BMF 2001;322:358.

8 Jolly B, McAvoy P, Southgate L. GMC's proposals for revalidation. Effective revalidation system looks at how doctors practise and quality of patients' experience. BMF 2001;322:358-9.

9 Martin D, Harrison P, Joesbury H, Wilson R. Appraisal for General Practitioners. Sheffield: Sheffield University, School of Health and Related Research 2001.

10 Norusis MJ. SPSS Base Manual 4.0. Chicago: SPSS Inc. 1990.

11 General Medical Council. Good Medical Practice. London: General Medical Council 1997.
12 Weightman J. Managing People in the Health Service. London: Institute of Personnel Development 1996.

13 Latham GP, Wexley KN. Increasing Productivity Through Performance Appraisal. Reading, Massachusetts: Addison-Wesley 1981.

14 Riley W. Appraising appraisal. BMF Career Focus 1998;317:2.

15 The Standing Committee on Postgraduate Medical and Dental Education (SCOPME). Appraising Doctors and Dentists in Training: a Working Paper for Consultation. London: SCOPME 1996.

16 Oxley J. Appraising doctors and dentists in training. BMF Career Focus 1997;315:S2.

17 Ramsey PG, Wenrich MD, Carline JD, Inui TS, Larson EB, LoGerfo JP. Use of peer ratings to evaluate physician performance. FAMA 1993;269:1655-60.

18 Brown SP, Leigh TW. A new look at psychological climate and its relationship to job involvement, effort and performance. F Appl Psychol 1996;81:358-68.

19 Charlton R. Continuing professional development and training. BMf Career Focus 2001;323:7309.

20 Harrison R. Training and Development. London: Institute of Personnel Management 1988.

Received 20 May 2002; editorial comments to authors 5 September 2002; accepted for publication 20 November 2002 